\title{
Debate Forum: Carnitine Supplements Have Not Been Demonstrated as Effective in Patients on Long-Term Dialysis Therapy
}

\author{
Garry J. Handelman \\ University of Massachusetts, Lowell, Mass., USA
}

\section{Key Words}

Carnitine supplements $\cdot$ End-stage renal disease $\cdot$ Erythropoietin dose

\begin{abstract}
The database for carnitine supplements in dialysis includes no large-scale randomized trials and no registered trials. Medical practitioners prefer to make treatment decisions based on the outcome of randomized clinical trials, with appropriate controls. Furthermore, registered trials provide a further level of integrity, since trial registration avoids publication bias by ensuring that all outcomes are reported, including trials that are not completed. Positive effects reported from carnitine administration in dialysis patients include decreased erythropoietin dose, increased hematocrit, less intradialytic hypotension, and less fatigue. The evidence for carnitine effectiveness is limited to trials that are mostly open-label and that include no more than a total of 1,000 patients. An analysis of recent carnitine administrations to patients in a large dialysis practice database indicates no overall change in hemoglobin or erythropoietin dose following 6 months of carnitine administration. As outcomes of controlled trials with appropriate power to examine for the benefits of carnitine are not yet available, the dialysis practitioner cannot justify the administration of carnitine.
\end{abstract}

Copyright @ 2006 S. Karger AG, Basel

\section{KARGER}

Fax +4161306 1234

E-Mail karger@karger.ch

www.karger.com

\section{Introduction}

The standards employed by medical practitioners to make patient care decisions have evolved with the development of the randomized clinical trial. These trials are customarily powered in advance to distinguish the effects of different treatments, and are designed to equip clinicians with improved ability to make decisions. Large study designs in hemodialysis patients have been recently employed with atorvastatin (1,250 patients) [1], darbepoetin- $\alpha$ (1,500 patients) [2], and a vitamin D analogue, paracalcitol (263 patients) [3].

These large study designs have intrinsic superiority over the strategy of using meta-analyses to achieve large patient numbers, because of the key limitation in metaanalysis, which is the problem of publication bias. Any survey that reviews a set of published trials needs to address the fact that unsuccessful trials may not reach publication; corporate sponsorship and academic aspirations conspire to stop trials from being completed if preliminary data are not supportive of the study hypothesis. Very large trials, with the power to achieve strong $p$ values, can overcome that bias. Even more rigor is achieved by a survey of trials that were registered prior to commencement, which allows the clinician to determine the fraction of trials that succeeded, as well as those trials which were started but not concluded. The carnitine data set includes neither highly powered large trials, nor registered trials. This set of published results cannot inspire confidence among clinicians. 
Long-term trials that use carnitine must be placebocontrolled, since the progressive improvement in standards of care for dialysis patient has led to widespread decreases in anemia, improvement in quality of life, and other benefits. These improvements in dialysis care will be reflected in positive changes for patients given carnitine for several years, concurrent with patients not given carnitine.

\section{Indications Proposed for Carnitine}

\section{Erythropoietin Resistance}

As early as 1982 [4], before the era of erythropoietin (EPO) use, there were suggestions that carnitine supplementation might benefit hematological indicators in endstage renal disease (ESRD) patients. No satisfactory mechanism has been put forth for such an effect. Several small trials have indicated that carnitine supplementation might benefit some patients, but these trials have not reached significance.

Kletzmayr et al. [5] evaluated the effects of intravenous carnitine on 20 hemodialysis patients and compared them with 20 placebo-treated controls. These patients were not selected for EPO resistance. Two doses of carnitine ( $5 \mathrm{mg} / \mathrm{kg}$ in 15 patients and $20 \mathrm{mg} / \mathrm{kg}$ in 5 patients) were utilized. There was no overall effect; however, the EPO dose decreased in 8 of the 20 carnitine-treated patients, but none of these changes achieved significance.

Labonia [6] administered carnitine and placebo to 13 patients each in a randomized double-blind design. The average EPO dose decreased by $37 \%$ in the treatment group, but did not change in the control group.

It would be highly appropriate to repeat this type of intervention in a larger controlled trial.

A review of EPO doses was conducted among 160 ESRD patients receiving carnitine in a large dialysis practice in the United States (Renal Research Institute, New York, N.Y.). This review indicated that among the 59 patients who received carnitine for more than 6 months, there was a slight $(+12 \%)$ increase in EPO dose versus EPO baseline requirements.

\section{Intradialytic Hypotension}

There is one published trial of the effects of carnitine on intradialytic hypotension that studied 44 patients treated with carnitine and 38 controls [7]. This study found an improvement in treated patients, but in the 15 years that have elapsed since that trial, no other reports of benefit for this disorder have been published. This re- port in 1990 was the primary basis for the 2003 National Kidney Foundation consensus panel [8] that recommended the use of carnitine for the treatment of hypotensive episodes during dialysis.

In 1982, Casciani et al. [9] administered $1 \mathrm{~g}$ of carnitine/day, orally, in a double-blind design, and found less hypotension in 9 treated subjects than in 9 controls. All other trials with hypotension have been small, open-label trials.

\section{Muscle Weakness and Fatigue}

The best established function of carnitine is the transport of fatty acids across the mitochondrial membranes, to be used as a substrate for $\beta$-oxidation. Therefore, it is highly appropriate to examine the effects of carnitine on muscle function. On theoretical grounds, it is unlikely that the degree of carnitine depletion experienced by patients on hemodialysis would inhibit the transport of acylcarnitines into the mitochondria. The Michaelis constant for carnitine palmitoyltransferase- 1 is about $100 \mu M$ [10]. In ESRD patients, muscle carnitine levels may decline from $2 \mathrm{~m} M$ (healthy controls) to $1 \mathrm{~m} M$ (dialysis patients) [11]. Since carnitine levels in ESRD are maintained well above the Michaelis constant for the formation of carnitine derivatives with fatty acids, impaired transport of fatty acids seems unlikely. In earlier studies [12], carnitine supplements given to hemodialysis patients were found to restore muscle carnitine levels to normal, but there was no effect on the efficiency of fatty acid oxidation by muscle specimens obtained from biopsy.

In a carefully designed trial of effects of carnitine on muscle function, Vaux et al. [13] could not show any improvements in strength, or decreases in fatigue, compared with patients given placebo.

\section{Conclusions}

The clinician, making his decisions based on a number of small trials, may feel inclined to experiment with carnitine supplementation. Given the reported examples of benefit, this is certainly intriguing. However, there are no published indications as to which patients benefit, and long-term monitoring will be required. In addition, because of regression to the mean, there is a possibility that the patient will improve without any intervention. The Medicare system requires dialysis clinics to record both carnitine and EPO doses for patients covered by Medicare reimbursement; the review of clin- 
ic databases provides an important opportunity for the evaluation of changes in EPO requirements for patients who have received carnitine with Medicare reimbursement.

The cost of carnitine therapy is borne by Medicare, and the profits to the clinic enable the intervention to be profitable. There is little additional effort, since many other drugs are also administered intravenously during treatment, except the need to search for changes in patient status that result from carnitine usage. Based on such a speculative trial, the clinician could be encouraged that carnitine might benefit the occasional patient. However, published data cannot support the general use of this intervention. We look forward to a database of registered carnitine trials, which ensures that all studies that are initiated can be reviewed for clinical evidence. With larger trials, and a registration to avoid publication bias, the clinician should have the objective means needed to assess the utility of carnitine supplements for ESRD patients.

\section{References}

-1 Wanner C, Krane V, Marz W, Olschewski M, Mann JF, Ruf G, Ritz E: Atorvastatin in patients with type 2 diabetes mellitus undergoing hemodialysis. N Engl J Med 2005;353:238248.

$>2$ Brunkhorst R, Bommer J, Braun J, Haag-Weber M, Gill C, Wagner J, Wagener T: Darbepoetin alfa effectively maintains haemoglobin concentrations at extended dose intervals relative to intravenous or subcutaneous recombinant human erythropoietin in dialysis patients. Nephrol Dial Transplant 2004;19:12241230.

-3 Sprague SM, Llach F, Amdahl M, Taccetta C, Batlle D: Paricalcitol versus calcitriol in the treatment of secondary hyperparathyroidism. Kidney Int 2003;63:1483-1490.

$\checkmark 4$ Trovato GM, Ginardi V, Di Marcoo V, Dell'Aira E, Corsi M: Long-term L-carnitine treatment of chronic anaemia of patients with end-stage renal failure. Curr Ther Res 1982;31: 1042-1049.
Kletzmayr J, Mayer G, Legenstein E, HeinzPeer G, Leitha T, Horl WH, Kovarik J: Anemia and carnitine supplementation in hemodialyzed patients. Kidney Int 1999;69(suppl): S93-S106.

$\checkmark 6$ Labonia WD: $L$-carnitine effects on anemia in hemodialyzed patients treated with erythropoietin. Am J Kidney Dis 1995;26:757-764.

>7 Ahmad S, Robertson HT, Golper TA, Wolfson M, Kurtin P, Katz LA, Hirschberg R, Nicora R, Ashbrook DW, Kopple JD: Multicenter trial of $L$-carnitine in maintenance hemodialysis patients. 2. Clinical and biochemical effects Kidney Int 1990;38:912-918.

$>8$ Eknoyan G, Latos DL, Lindberg J: Practice recommendations for the use of $L$-carnitine in dialysis-related carnitine disorder. Nationa Kidney Foundation Carnitine Consensus Conference. Am J Kidney Dis 2003;41:868-876.

$\checkmark 9$ Casciani C, Caruso U, Cravotto E, Corsi M, Maccri F: Beneficial effects of $L$-carnitine in post-dialysis syndrome. Curr Ther Res 1982; 32:116-127.
10 Stanley CA: Carnitine deficiency disorders in children. Ann NY Acad Sci 2004; 1033:42_ 51.

11 Debska S, Kawecka A, Wojnarowski K, Prajs J, Malgorzewicz S, Kunicka D, Zdrojewski Z, Walysiak S, Lipinski J, Rutkowski B: Correlation between plasma carnitine, muscle carnitine and glycogen levels in maintenance hemodialysis patients. Int $\mathbf{J}$ Artif Organs 2000;23: 90-96.

12 Siami G, Clinton ME, Mrak R, Griffis J, Stone W: Evaluation of the effect of intravenous $L$ carnitine therapy on function, structure and fatty acid metabolism of skeletal muscle in patients receiving chronic hemodialysis. Nephron 1991;57:306-313.

13 Vaux EC, Taylor DJ, Altmann P, Rajagopalan B, Graham K, Cooper R, Bonomo Y, Styles P: Effects of carnitine supplementation on muscle metabolism by the use of magnetic resonance spectroscopy and near-infrared spectroscopy in end-stage renal disease. Nephron Clin Pract 2004;97:c41-c48. 